\title{
On transparent and opake arsenious acid
}

\section{Bussy}

To cite this article: M. Bussy (1848) On transparent and opake arsenious acid, Philosophical Magazine Series 3, 32:216, 398-399, DOI: 10.1080/14786444808646008

To link to this article: http://dx.doi.org/10.1080/14786444808646008

$$
\text { 册 Published online: } 30 \text { Apr } 2009 .
$$

Submit your article to this journal

LII Article views: 2

Q View related articles $\asymp$ 
are dissolved in the water; the liquor then contains selenious acid and hydrochloric acid resulting from the decomposition of the protoand deuto-chloride of selenium in water.

On the addition of hydrochloric acid, and then sulphite of ammonia, this salt is decomposed by the hydrochloric acid, and the sulphurous acid which is set free precipitates the selenium in the state of a grayish powder, which afterwards becomes yellowish-white.

M. Trez thinks that the seleniate of potash may either have been fraudulently added, or that it was extracted with the iodine.-Journ. de Ch. Méd.. Avril 1848.

\section{ON TRANSPARENT AND OPAKE ARSENIOUS ACID. BY M. BUSSY.}

It is well known that arsenious acid exists in the different states above-mentioned, and also that the transparent variety becomes opake; it has been stated that the former is less soluble in water than the latter. By performing experiments to determine this point, M. Bussy has arrived at the following conclusions:-

lst. 'That the transparent acid, far from being less soluble than the opake, as stated by several chemists, is, on the contrary, much more so; the difference is nearly as 3 to 1 , at the temperature of about $55^{\circ} \mathrm{F}$.; thus a litre of water which dissolves 40 grammes of the transparent acid dissolves only 12 to 13 grammes of the opake.

2nd. That the transparent acid dissolves much more rapidly than the opake.

3rd. That neither of these acids possesses a perfectly constant degree of solubility.

4th. That the opake acid is converted into the transparent by long-continued boiling in water, that is to say, it acquires the same degree of solubility as the transparent acid, which is such that 100 grammes of acid dissolve in a litre of water at $212^{\circ}$.

5th. That under the influence of water and a low temperature the transparent is converted into the opake acid.

$6 \mathrm{th}$. That the mixture of the two varieties of acid in the same solution explains the anomalies observed in the solubility of arsenious acid.

7th. That division which facilitates the solution of the opake arsenious acid without increasing its solubility, considerably diminishes that of the transparent acid, and to such an extent, that the latter, reduced to fine powder and levigated, is not sensibly more soluble in the cold than the opake acid; this effect undoubtedly results from a transformation which it undergoes, either at the moment of pulverizing, or of its contact with water.

8th. That the acid which has become opake by the slow transformation of the transparent, by the action of ammonia, and the acid crystallized in water, are similarly acted upon by water, and appear to belong to the same variety.

9 th. That under the influence of dilute hydrochloric acid, the opake acid dissolves more slowly than the transparent; this circumstance, which modifies the nature of the products formed during 
solution, explains why the phænomena observed by M. Henri Rose during the crystallization of the transparent acid, are not in general so intense in the solution of the opake acid.

10th. That the difference which has been observed in the action of the two arsenious acids on the tincture of litmus is merely apparent.-Journ. de Chim. Méd., Fevrier ] 848.

\section{METEOROLOGICAL OBSERVATIONS FOR MARCH 1848.}

Chiswick.-BIarch 1. Constant rain : barometer very low, 2. Cloudy and damp. 3. Very fine. 4. Hoar-frost : slight haze. 5. Rain. 6. Cloudy : fine: overcast. 7. Foggy : slight haze : clear. 8. Frosty and foggy : overcast : slight rain. 9. Overcast and mild. 10. Rain : fine : cloudy. 11. Boisterous, with heavy showers. 12. Showery. 13. Cloudy and cold: heavy rain at night. 14. Fine: clear and frosty. 15. Overcast. 16, 17. Rain. 18. Foggy : fine. 19. Foggy: fine: showery. 20. Heavy rain. 21. Hazy and damp: cloudy : showery : clear : frosty at night. 22 . Cloudless : boisterous, with rain at night. 23,24 . Cloudy and fine. 25. Uniform haze : cloudy and fine. 26. Overcast : slight rain. 27. Foggy : drizzly. 28. Very fine: rain at night. 29. Hazy and damp : fine. 30 . Foggy : slight rain : clear. 31. Hazy : very fine : clear at night.

Mean temperature of the month $42^{\circ} \cdot 5$

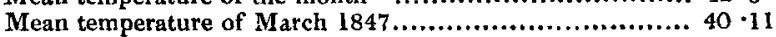

Mean temperature of March for the last twenty years......... $42 \cdot 8$

Average amount of rain in March ........................ 1.36 inch.

Boston.-March 1. Cloudy : rain last night. 2. Cloudy : rain P.M. 3. Fine : rain P.M. 4. Fine. 5. Rain. 6-9. Cloudy. 10, i1. Cloudy: rain A.M. 12. Cloudy : rain A.M. and P.M. 13. Fine: rain 1.M. 14, 15. Fine. 16. Rain : rain A.M. and P.M. 17. Cloudy : rain A.M. and P.M. 18. Cloudy. 19. Cloudy: rain P.M. 2O. Fine. 21. Rain : rain A.M. and P.M. 22. Fine : rain P.M. 23-25. Cloudy. 26. Cloudy : rain P. M. 27. Cloudy : rain A.s. and P.M. 28. Rain: rain A.M. 29. Cloudy : rain A.M. 30. Fine: rain p.M. 31. Rain.

Applegarlh Manse, Dumfries-shire.-- March 1. Fair, but cloudy and raw. 2, 3. Fair and clear: raw frost A.M. 4. Fair and clear: hard frost A.M. : rain $\mathbf{P}$ M. 5-7. Cloudy, but fair. 8. Fine: wet A.M.: cleared. 9. Rain in the night: cleared P.M. 10. Showers : hail. 11. Frequent showers : hills covered with snow. 12. Clear cold day. 13. Clear cold day : frost A M.: fine. 14. Frost A.x.: cloudy: rain P.M. 15. Frequent showers. 16. Fair, but chilly. 17. Rain during night: drizzling A.M. 18. Rain early A.M. : fine. 19. Rain and hail: snow P.M. 20. Frost: hail : thaw P.M. 21. Frost: snow on hills: hail. 22. Frost A.M.: heavy rain P.M. 23. Frequent showers. 24. Very fine: warm. 25. Very fine. 26. Hain nearly all day. 27. Very fine. 28. Wet till noon : cleared. 29. Fine : clear: cold. 30. Fine all day: light clouds. 31. Very fine : clear and warm.

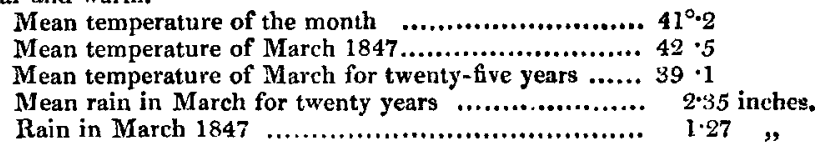

Sandwick Manse, Orkney.-March 1. Clear. 2. Clear: cloudy. 9. Clear. 4. Damp. 5. Damp : drops. 6. Damp : cloudy. 7. Cloudy. 8. Showers : clear : aurora. 9. Bright : showers. 10. Clear : hoar-frost. 11. Cloudy : showers. 12. Bright: clear. 13. Clear : hoar-frost, 14. Cloudy : rain. 15. Bright : clear: aurora. 16. Showers. 17. Cloudy : showers. 18. Bright : cloudy. 19. Bright : clear : aurora. 20. Snow : clcar : aurora. 21. Clear : frost : cloudy. 22. Clear: cloudy. 23. Rain : drops. 24. Clear: cloudy. 25. Bright : cloudy. 26. Rain, 27. Clear: fog. 28. Fog : rain. 29, 30. Bright : cloudy. 31. Clear : cloudy. 